\title{
Public Health Messages Associated with Low UV Index Values Need Reconsideration
}

\author{
Maria Lehmann ${ }^{1} \mathbb{D}$, Annette B. Pfahlberg ${ }^{1} \mathbb{D}$, Henner Sandmann ${ }^{2}$, Wolfgang Uter ${ }^{1}$ and \\ Olaf Gefeller $1, *$ (D) \\ 1 Department for Medical Informatics, Biometry and Epidemiology, Friedrich-Alexander-Universität \\ Erlangen-Nürnberg (FAU), Waldstr. 6, 91054 Erlangen, Germany; maria.lehmann@fau.de (M.L.); \\ annette.pfahlberg@fau.de (A.B.P.); wolfgang.uter@fau.de (W.U.) \\ 2 uv-tech consulting, Tönniesstr. 9, 24106 Kiel, Germany; sandmann@uv-tech.de \\ * Correspondence: olaf.gefeller@fau.de; Tel.: +49-9131-85-22750
}

Received: 29 April 2019; Accepted: 7 June 2019; Published: 12 June 2019

\begin{abstract}
Overexposure to ultraviolet (UV) radiation is the main modifiable risk factor for skin cancer. The Global Solar Ultraviolet Index (UVI) was introduced as a tool to visualize the intensity of UV radiation on a certain day, which should enable and encourage people to take appropriate protective measures. The 'low' exposure category of the UVI, defined by a rounded UVI value of 0,1 or 2, was linked to the health message 'No protection required' by the World Health Organization and partner organizations. However, published evidence corroborating this advice is not available. To evaluate the erythemal risk of low UVI days, we analyzed 14,431 daily time series of ambient erythemal irradiance data measured at nine stations of the German solar UV monitoring network during the years 2007-2016. We analyzed the proportion of days in the sample for which ambient erythemal doses calculated for various time intervals exceed average minimal erythemal doses (MEDs) of the Fitzpatrick skin phototypes I-VI to assess the potential for erythema arising from sun exposure on days with low UVI values. Additionally, we calculated for each day the minimum exposure duration needed to receive one MED. Our results indicate that on days with a UVI value of 0 , risk of erythema is indeed negligible. Conversely, the abovementioned health message appears misleading when melano-compromised individuals (skin type I and II) spend more than 1.5 hours outdoors on days with a UVI value of 2. Under rare circumstances of prolonged exposure, MEDs of the two most sensitive skin types can also be exceeded even on days with a UVI value of 1 . Hence, current WHO guidance for sun protection on days with low UVI values needs reconsideration.
\end{abstract}

Keywords: ultraviolet rays; health promotion; radiation monitoring; sun protection; evidence-based public health

\section{Introduction}

Ultraviolet (UV) radiation, approaching Earth every day in the form of sunlight, has officially been classified as carcinogenic to humans by the International Agency for Research on Cancer [1]. Overexposure to UV radiation is responsible for a substantial proportion of melanoma and nonmelanoma skin cancers [2], the incidence rates of which have been increasing for decades worldwide [3,4]. This implies that skin cancer is largely preventable using appropriate sun protection. Trying to exploit this preventive potential, two crucial questions have been addressed by a variety of approaches [5-9]: "When is sun protection needed?" and "How can it be effectively implemented?" The former aspect requires people to identify situations calling for different levels of sun protection. This is hampered by humans' lack of a sensory organ for UV radiation and the positive correlation 
between temperature and UV radiation being too low $[10,11]$ to allow substituting temperature as a valid proxy for the level of UV radiation in daily life.

To provide an easily understandable measure of the intensity of solar UV radiation for the public, the World Health Organization (WHO), the World Meteorological Organization (WMO), the United Nations Environment Programme (UNEP) and the International Commission on Non-Ionizing Radiation Protection (ICNIRP) introduced the Global Solar UV Index (UVI) in 1995 [12], based on an earlier proposal developed by a Canadian government agency [13]. This index is a unitless quantity (reported as rounded to the nearest integer), proportional to the daily maximum $30 \mathrm{~min}$ moving average of the intensity of erythemally weighted [14,15] solar UV irradiance $\left(E_{e r}\right)$ at surface level [16]. The primary purpose of the UVI at the time of its launch was to create an internationally standardized concept for monitoring of long-term changes in ground-level UV radiation, but its additional public health use was already on the agenda [17]. However, it was not until 2002 that WHO and its partner organizations published a practical guide providing information on how the concept of the UVI could be extended to serve as a public awareness tool [16]. The UVI guidance included a classification of the UVI scale into five exposure categories which were linked to specific health messages (Figure 1).

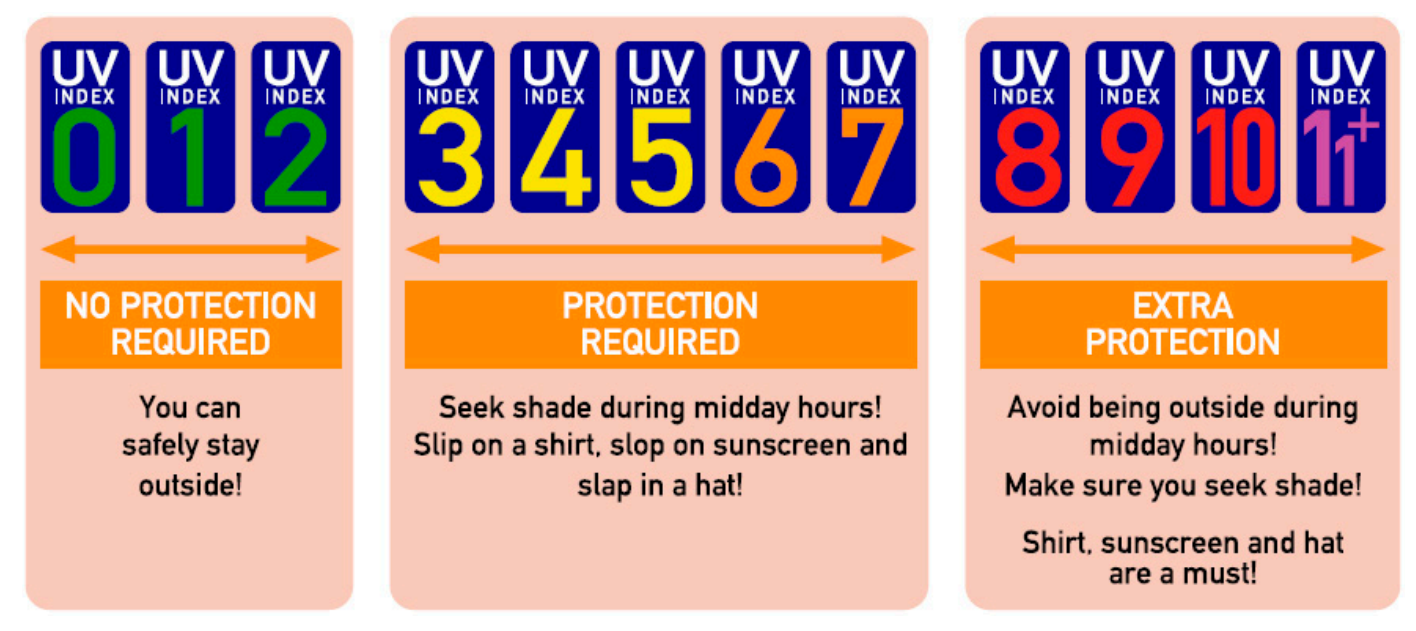

Figure 1. UV Index (UVI) guidance according to the WHO. Figure modified from [16]. The modification consists of the explicit graphical representation of the value zero in the 'low exposure' category, which is not part of the original WHO figure but is mentioned to belong to this category in the text [16].

These messages are intended to be valid for various exposure durations and skin phototypes but focus on fair-skinned people [16]. The exposure category 'low', comprising rounded UVI values from 0 to 2, is related to the simple messages 'No protection required' and 'You can safely stay outside!' As these messages imply harmlessness of sun exposure on such days, there should be a solid evidence base for this clear-cut threshold to not lull people into a false sense of security. Unfortunately, no explanation on how the classification of the UVI scale into the different exposure categories was derived and how the adequacy of the linked health messages was validated has been given. The aim of our study was thus to evaluate potential erythemal effects of exposure to solar UV radiation on days with low UVI values, especially considering the difference in susceptibility to UV radiation-induced damage between distinct skin phototypes. To this end, we analyzed a large high-quality dataset of measurements of erythemal irradiance on days belonging to the low exposure category to quantify ambient erythemal UV doses attained during these days in detail.

\section{Materials and Methods}

\subsection{Data Sources}

Our dataset consists of measurements of diurnal courses of ambient $\mathrm{E}_{\mathrm{er}}$ over the ten-year period from 2007 until 2016. Those were conducted by nine stations of the German solar UV monitoring 
network, which is managed by the German Federal Office for Radiation Protection and the German Federal Environmental Agency. Further institutions associated with this UV monitoring network are the German Weather Service, the Federal Institute for Occupational Safety and Health, the Department for Medical Climatology at the University of Kiel, the Labor Inspectorate of Lower Saxony, and the Bavarian Environmental Agency.

As can be seen in Figure 2, the measuring stations belonging to the network are located all over Germany, ranging from a geographical latitude of $47.91^{\circ} \mathrm{N}$ to $54.92^{\circ} \mathrm{N}$, a geographical longitude of $7.91^{\circ} \mathrm{E}$ to $14.11^{\circ} \mathrm{E}$, and a height above sea level of 4 to $1205 \mathrm{~m}[18,19]$. The geographic distribution of the stations was chosen in such a way that all major climate regions in Germany were covered: Germany's North Sea coast (with pure marine air) and Baltic Sea coast, the North German Plain, the Central Uplands, the Ruhr district and the Rhine valley (both of which suffer from anthropogenically polluted air), and the Alpine foreland. In this way, the locations of the measuring stations provide a representative sample of places in Germany where people expose themselves to the sun in their working life or in their leisure time.

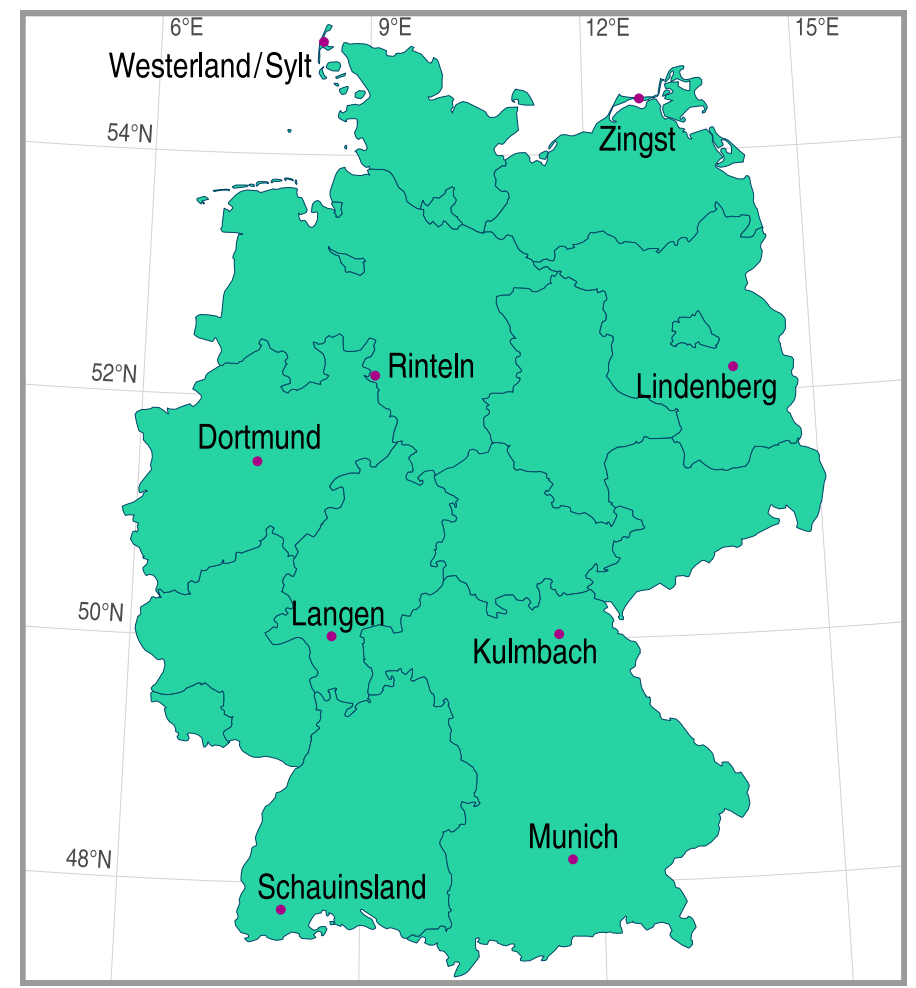

Figure 2. Map of Germany showing the geographical position of the nine stations of the German solar UV monitoring network which provided erythemal irradiance data.

At each station, measurements of solar UV spectra (leading to $E_{\text {er }}$ after weighing with the erythema reference action spectrum [14,15]) were conducted every 6 min each day between sunrise and sunset. The daily UVI value was then calculated by taking the maximum 30 min moving average of $\mathrm{E}_{\mathrm{er}}$, multiplying it by a constant equal to $40 \mathrm{~m}^{2} / \mathrm{W}$, and rounding this to the nearest integer using the "round half up" approach. Double monochromator spectroradiometers (DTM300 or DM150, Bentham, Reading, UK) were used for undertaking the UV measurements. The concept for quality assurance of these measurements includes both regular wavelength calibrations of the spectroradiometers by means of mercury lamps and calibration of the systems' sensitivity with calibration standards (150 W or $200 \mathrm{~W}$ halogene lamps), traceable to secondary standards of the German National Metrology Institute (Physikalisch Technische Bundesanstalt (PTB), Brunswick, Germany). Calibrations are carried out with an interactive calibration software designed specifically for the UV monitoring network. Further 
details on the stations, the measuring instruments, and criteria for technical quality that were applied to the data can be found elsewhere [20].

As similar UVI conditions can occur concurrently at multiple stations of the network, several calendar days appear more than once in our dataset. Therefore, from here, the term 'day' in this paper does not refer to a single specific calendar day, but rather to our unit of observation, which is one diurnal course of $E_{e r}$ during this calendar day at one specific station of the network.

\subsection{Statistical Analysis}

To enhance comparability between data from different stations and to compensate for annual variation of solar noon at each station, we transformed the time base of the data from Coordinated World Time to Local Solar Time (LST), where solar noon always occurs at 12:00. To analyze potential UV hazards on days with low UVI values, erythemal irradiance data were linearly interpolated and integrated over certain time intervals to calculate erythemal doses $\left(\mathrm{H}_{\mathrm{er}}\right)$ received during that period. The considered intervals were defined as (equivalently to [20]) 11:45-12:15, 11:30-12:30, 11:00-13:00, 10:30-13:30, and 10:00-14:00, corresponding to $0.5,1,2,3$, and $4 \mathrm{~h}$ centered around solar noon, respectively. Ambient erythemal doses were also calculated for the intervals 08:00-10:00, 14:00-16:00, 07:30-10:30, and 13:30-16:30, i.e., $2 \mathrm{~h}$ and $3 \mathrm{~h}$ intervals, each centered $3 \mathrm{~h}$ before and after noon, respectively. Additionally, the erythemal dose for the total day (sunrise to sunset) was computed.

Descriptive information on the distribution of erythemal doses is reported as median accompanied by the 10th (p10) and 90th (p90) percentile, taking account for skewness of the data. To assess the potential hazard from these doses we report the percentages of days in our sample for which average minimal erythemal doses (MEDs) of Fitzpatrick skin types I through VI [21], as shown in Table 1, are exceeded in the given time intervals. One MED is the amount of (solar) UV exposure, which produces minimal perceptible reddening of the skin (solar erythema) $24 \mathrm{~h}$ after exposure. Hence, one MED can be considered a short-time maximum dose that should not be exceeded to prevent detrimental effects of UV radiation on the human body [22].

In a second step, we calculated for each day the minimum exposure duration to receive one $M E D, t_{M E D, m i n}$ (again, for all six skin types). We obtained $t_{M E D, m i n}$ by computing all time intervals to exceed one skin type specific MED using an integration procedure with variable lower and upper bounds, and then taking the interval with the minimal length for each day. The distributions of

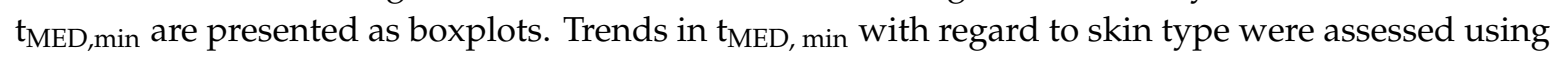
the nonparametric Jonckheere-Terpstra trend test. $p$-values less than 0.05 (two-sided) were considered significant. Data analysis was performed using the statistical software package R (Version 3.5.1, R Foundation for Statistical Computing, Vienna, Austria) [23].

Table 1. Column 1: Fitzpatrick skin types [21], column 2: specific skin response to sun exposure [24], column 3: further classification of the skin types [25], column 4: average minimal erythemal doses (MEDs) corresponding to the skin types according to the International Commission on Non-Ionizing Radiation Protection (ICNIRP) [25]. MEDs given in terms of standard erythema doses (1 SED = 1 standard erythema dose $=100 \mathrm{~J} / \mathrm{m}^{2}$ weighted with the International Commission on Illumination (CIE) erythema reference action spectrum [14]).

\begin{tabular}{|c|c|c|c|}
\hline Skin Type & Skin Response to Sun Exposure & Classes of Individuals & MED (in SED) \\
\hline I & $\begin{array}{l}\text { Burns easily and severely (painful burn); } \\
\text { tans little or none and peels }\end{array}$ & \multirow[t]{2}{*}{ Melano-compromised } & 2.0 \\
\hline II & $\begin{array}{l}\text { Usually burns easily and severely (painful } \\
\text { burn); tans minimally or lightly, also peels }\end{array}$ & & 2.5 \\
\hline III & Burns moderately and tans & \multirow{2}{*}{ Melano-competent } & 4.0 \\
\hline IV & Burns minimally, tans easily & & 6.0 \\
\hline $\mathrm{V}$ & Rarely burns, tans easily and substantially & \multirow{2}{*}{ Melano-protected } & 8.5 \\
\hline VI & Never buns and tans profusely & & 10.0 \\
\hline
\end{tabular}




\section{Results}

\subsection{Dataset Description}

Our final dataset consisted of erythemal irradiance data of 4961 days with a rounded UVI value of 0 (UVI 0 days), 6117 days with a rounded UVI value of 1 (UVI 1 days), and 3353 days with a rounded UVI value of 2 (UVI 2 days).

The distributions of UVI 0, UVI 1, and UVI 2 days with regard to the year of their occurrence are given in Table 2. The maximum number of UVI 0 days originates from 2009 ( $\mathrm{N}=570 ; 11.5 \%$ ), the minimum number of such days occurred in $2014(\mathrm{~N}=447 ; 9.0 \%)$. The frequency of UVI 1 days in our sample is highest for the year $2010(\mathrm{~N}=694 ; 11.3 \%)$ and lowest for the year $2014(\mathrm{~N}=532 ; 8.7 \%)$. The distribution of UVI 2 days has its maximum in $2008(\mathrm{~N}=427 ; 12.7 \%)$ and its minimum in $2009(\mathrm{~N}=258 ; 7.7 \%)$.

Table 2. Absolute (N) and relative (\%) frequency distributions of UVI 0, 1, and 2 days, according to year of occurrence.

\begin{tabular}{ccccccc}
\hline \multirow{2}{*}{ Year } & \multicolumn{2}{c}{ UVI 0 } & \multicolumn{2}{c}{ UVI 1 } & \multicolumn{2}{c}{ UVI 2 } \\
\cline { 2 - 7 } & $\mathbf{N}$ & \% & N & \% & N & \% \\
\hline 2007 & 526 & 10.6 & 616 & 10.1 & 343 & 10.2 \\
2008 & 509 & 10.3 & 585 & 9.6 & 427 & 12.7 \\
2009 & 570 & 11.5 & 534 & 8.7 & 258 & 7.7 \\
2010 & 533 & 10.7 & 694 & 11.3 & 361 & 10.8 \\
2011 & 482 & 9.7 & 618 & 10.1 & 307 & 9.2 \\
2012 & 486 & 9.8 & 650 & 10.6 & 332 & 9.9 \\
2013 & 488 & 9.8 & 632 & 10.3 & 322 & 9.6 \\
2014 & 447 & 9.0 & 532 & 8.7 & 324 & 9.7 \\
2015 & 453 & 9.1 & 604 & 9.9 & 340 & 10.1 \\
2016 & 467 & 9.4 & 652 & 10.7 & 339 & 10.1 \\
Total & 4961 & 100.0 & 6117 & 100.0 & 3353 & 100.0 \\
\hline
\end{tabular}

The monthly distributions of UVI 0, UVI 1, and UVI 2 days are given in Table 3 . The unimodal distribution of UVI 0 days with its maximum in December $(\mathrm{N}=1949 ; 39.3 \%)$ is due to the fact that the winter solstice with greatest solar zenith angle (SZA) is around December 21 on the Northern hemisphere. Monthly distributions of UVI 1 and UVI 2 days, respectively, are bimodal with the two maxima for UVI 1 days occurring in February $(\mathrm{N}=1526 ; 24.9 \%)$ and November $(\mathrm{N}=1281 ; 20.9 \%)$ and for UVI 2 days in March $(\mathrm{N}=1061 ; 31.6 \%)$ and October $(\mathrm{N}=913,27.2 \%)$. The frequency of UVI 0 and UVI 1 days during spring and summer months (with seasons defined astronomically [26], i.e., March $20 / 21$ until September 22/23) is very low ( $0.4 \%$ and $7.7 \%$ respectively); only UVI 2 days are represented more often $(37.0 \%)$ in our sample during this period.

Table 3. Absolute (N) and relative (\%) frequency distributions of UVI 0, 1, and 2 days, according to month of occurrence.

\begin{tabular}{ccccccc}
\hline \multirow{2}{*}{ Month } & \multicolumn{2}{c}{ UVI 0 } & \multicolumn{2}{c}{ UVI 1 } & \multicolumn{2}{c}{ UVI 2 } \\
\cline { 2 - 7 } & $\mathbf{N}$ & \% & N & \% & N & \% \\
\hline Jan & 1515 & 30.5 & 742 & 12.1 & 1 & 0.0 \\
Feb & 396 & 8.0 & 1526 & 24.9 & 249 & 7.4 \\
Mar & 54 & 1.1 & 674 & 11.0 & 1061 & 31.6 \\
Apr & 3 & 0.1 & 92 & 1.5 & 300 & 8.9 \\
May & 1 & 0.0 & 69 & 1.1 & 136 & 4.1 \\
Jun & 0 & 0.0 & 29 & 0.5 & 78 & 2.3 \\
Jul & 6 & 0.1 & 28 & 0.5 & 71 & 2.1 \\
Aug & 0 & 0.0 & 44 & 0.7 & 105 & 3.1 \\
Sep & 10 & 0.2 & 145 & 2.4 & 377 & 11.2 \\
Oct & 88 & 1.8 & 1047 & 17.1 & 913 & 27.2 \\
Nov & 939 & 18.9 & 1281 & 20.9 & 62 & 1.8 \\
Dec & 1949 & 39.3 & 440 & 7.2 & 0 & 0.0 \\
Total & 4961 & 100.0 & 6117 & 100.0 & 3353 & 100.0 \\
\hline
\end{tabular}




\subsection{Erythemal Doses and Proportion of Days Exceeding MEDs for Certain Time Intervals}

Table 4 shows the distribution of ambient erythemal doses received during fixed time intervals and the proportion of days for which one MED of skin types I to VI is exceeded in these intervals.

Table 4. Ambient erythemal UV doses $\left(\mathrm{H}_{\mathrm{er}}\right)$ calculated for different time intervals on days with a UVI value of 0,1 , and 2 and corresponding proportion of days with doses from those intervals exceeding one MED for the Fitzpatrick [21] skin types I to VI. (1 SED = 1 standard erythema dose $=100 \mathrm{~J} / \mathrm{m}^{2}$ weighted with the CIE erythema reference action spectrum [14]).

\begin{tabular}{|c|c|c|c|c|c|c|c|}
\hline \multirow{2}{*}{$\begin{array}{c}\text { Time Interval } \\
\text { (Local Solar Time, } \\
\text { Duration) }\end{array}$} & \multirow{2}{*}{$\begin{array}{l}\text { Her }_{\text {er SED); }} \\
\text { Median (p10, } \\
\text { p90 Percentile) }\end{array}$} & \multicolumn{6}{|c|}{ Proportion of Days Exceeding one MED for Skin Type (in \%) } \\
\hline & & I & II & III & IV & $\mathbf{V}$ & VI \\
\hline \multicolumn{8}{|l|}{ Before noon } \\
\hline \multicolumn{8}{|l|}{$8: 00-10: 00,2 \mathrm{~h}$} \\
\hline UVI 0 & $0.12(0.05,0.23)$ & 0 & 0 & 0 & 0 & 0 & 0 \\
\hline UVI 1 & $0.42(0.20,0.86)$ & 0.07 & 0 & 0 & 0 & 0 & 0 \\
\hline UVI 2 & $1.24(0.69,1.92)$ & 7.87 & 2.09 & 0 & 0 & 0 & 0 \\
\hline \multicolumn{8}{|l|}{$7: 30-10: 30,3 \mathrm{~h}$} \\
\hline UVI 0 & $0.19(0.09,0.36)$ & 0 & 0 & 0 & 0 & 0 & 0 \\
\hline UVI 1 & $0.67(0.34,1.31)$ & 1.03 & 0.15 & 0 & 0 & 0 & 0 \\
\hline UVI 2 & $1.90(1.11,2.85)$ & 44.32 & 19.92 & 0.89 & 0 & 0 & 0 \\
\hline \multicolumn{8}{|l|}{ Around noon } \\
\hline \multicolumn{8}{|l|}{$11: 45-12: 15,0.5 \mathrm{~h}$} \\
\hline UVI 0 & $0.11(0.05,0.19)$ & 0 & 0 & 0 & 0 & 0 & 0 \\
\hline UVI 1 & $0.32(0.20,0.54)$ & 0 & 0 & 0 & 0 & 0 & 0 \\
\hline UVI 2 & $0.74(0.43,1.00)$ & 0 & 0 & 0 & 0 & 0 & 0 \\
\hline \multicolumn{8}{|l|}{$11: 30-12: 30,1 \mathrm{~h}$} \\
\hline UVI 0 & $0.23(0.11,0.37)$ & 0 & 0 & 0 & 0 & 0 & 0 \\
\hline UVI 1 & $0.64(0.40,1.05)$ & 0 & 0 & 0 & 0 & 0 & 0 \\
\hline UVI 2 & $1.46(0.93,1.96)$ & 7.75 & 0 & 0 & 0 & 0 & 0 \\
\hline \multicolumn{8}{|l|}{$11: 00-13: 00,2 \mathrm{~h}$} \\
\hline UVI 0 & $0.44(0.21,0.70)$ & 0 & 0 & 0 & 0 & 0 & 0 \\
\hline UVI 1 & $1.24(0.80,2.03)$ & 10.99 & 0.49 & 0 & 0 & 0 & 0 \\
\hline UVI 2 & $2.83(1.92,3.80)$ & 87.89 & 68.65 & 5.37 & 0 & 0 & 0 \\
\hline \multicolumn{8}{|l|}{$10: 30-13: 30,3 \mathrm{~h}$} \\
\hline UVI 0 & $0.63(0.31,0.99)$ & 0 & 0 & 0 & 0 & 0 & 0 \\
\hline UVI 1 & $1.78(1.15,2.90)$ & 39.28 & 20.08 & 0 & 0 & 0 & 0 \\
\hline UVI 2 & $4.08(2.86,5.45)$ & 98.39 & 95.38 & 52.82 & 2.42 & 0 & 0 \\
\hline \multicolumn{8}{|l|}{ 10:00-14:00, $4 \mathrm{~h}$} \\
\hline UVI 0 & $0.79(0.39,1.23)$ & 0 & 0 & 0 & 0 & 0 & 0 \\
\hline UVI 1 & $2.24(1.43,3.64)$ & 60.72 & 39.82 & 4.51 & 0 & 0 & 0 \\
\hline UVI 2 & $5.14(3.71,6.88)$ & 99.79 & 99.14 & 84.01 & 26.39 & 0 & 0 \\
\hline \multicolumn{8}{|l|}{ After noon } \\
\hline \multicolumn{8}{|l|}{$14: 00-16: 00,2$ h } \\
\hline UVI 0 & $0.12(0.05,0.22)$ & 0 & 0 & 0 & 0 & 0 & 0 \\
\hline UVI 1 & $0.42(0.20,0.86)$ & 0.08 & 0 & 0 & 0 & 0 & 0 \\
\hline UVI 2 & $1.24(0.72,1.92)$ & 7.99 & 2.42 & 0 & 0 & 0 & 0 \\
\hline \multicolumn{8}{|l|}{$13: 30-16: 30,3 \mathrm{~h}$} \\
\hline UVI 0 & $0.19(0.08,0.36)$ & 0 & 0 & 0 & 0 & 0 & 0 \\
\hline UVI 1 & $0.67(0.33,1.32)$ & 1.32 & 0.25 & 0 & 0 & 0 & 0 \\
\hline UVI 2 & $1.92(1.16,2.85)$ & 44.68 & 20.34 & 0.95 & 0 & 0 & 0 \\
\hline \multicolumn{8}{|l|}{ Total day } \\
\hline \multicolumn{8}{|l|}{ Sunrise-Sunset } \\
\hline UVI 0 & $1.04(0.52,1.65)$ & 1.23 & 0.04 & 0 & 0 & 0 & 0 \\
\hline UVI 1 & $3.21(1.95,5.46)$ & 88.49 & 70.51 & 32.58 & 4.72 & 0.07 & 0.02 \\
\hline UVI 2 & $8.17(6.01,10.87)$ & 99.97 & 99.97 & 99.79 & 90.19 & 44.77 & 19.03 \\
\hline
\end{tabular}


Expectedly, exposure loads received either before or after noon yield a smaller erythemal dose than an interval of the same duration around noon for all considered UVI values. Further, due to the shift of our data to LST for normalization, intervals of equal length before and after noon lead to almost exactly equal doses.

The shortest interval considered, $30 \mathrm{~min}$ around noon, does not yield doses exceeding MEDs of any skin type on any day. The $1 \mathrm{~h}$ interval around noon does so only for the MED of skin type I on $7.75 \%$ of UVI 2 days.

On UVI 0 days, the MEDs of skin types III-VI are never exceeded, and for skin types I and II only for the total day interval and in only $1.23 \%$ and $0.04 \%$ of eligible days, respectively.

Regarding UVI 1 days, doses received during the 2 and $3 \mathrm{~h}$ intervals around noon are already larger than MEDs of the two sensitive skin types II, and especially I, for a considerable proportion ( $0.49 \%$ and $20.08 \%$ for skin type II, respectively, and $10.99 \%$ and $39.28 \%$ for skin type I, respectively) of days. The MED of skin type III is exceeded only for $4.51 \%$ of the $4 \mathrm{~h}$ intervals around noon and for $32.58 \%$ of the total day intervals. The latter interval is also the only one providing doses large enough to exceed the MEDs of skin types IV, V, and VI on $4.72 \%, 0.07 \%$, and $0.02 \%$ of eligible days, respectively.

Concerning UVI 2 days, even $2 \mathrm{~h}$ around noon pose a serious erythemal risk for skin type I and II, with nearly $88 \%$ and $69 \%$, respectively, of days giving doses exceeding the MED. By contrast, for skin types IV-VI, the same interval does not lead to the excess of one MED for any day in our sample. Erythemal doses from the $4 \mathrm{~h}$ interval around noon exceed MEDs of the melano-competent skin types III and IV in more than $80 \%$ and about one fourth of days, respectively. The total daily dose is higher than the MEDs of skin types I-IV for more than $90 \%$ of all UVI 2 days. Day-long exposure also leads to the MEDs of skin type V and VI being exceeded on $44.77 \%$ and about one fifth of UVI 2 days, respectively.

\subsection{Minimal Exposure Durations to Receive one MED}

For UVI 0 days, the daily minimum exposure durations needed to receive one MED ( $\left.t_{M E D, \min }\right)$ was extremely long for skin types I (median $7.2 \mathrm{~h}$ ) and II (MED exceeded for only $\mathrm{N}=2$ days, values of $t_{M E D, \min }: 9.0 \mathrm{~h}, 9.3 \mathrm{~h}$ ). One MED could not be received at all for skin types III-VI.

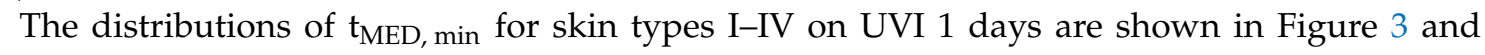
distributions of $t_{M E D, ~ m i n}$ for skin types I-VI on UVI 2 days are shown in Figure 4 . $t_{M E D \text {, min }}$ decreases as the UVI value increases, and the skin type decreases (i.e., becomes more UV sensitive). The distribution

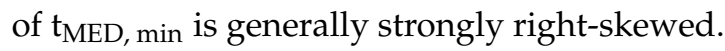

For UVI 1 days, median $\mathrm{t}_{\mathrm{MED}}$, min are quite long, starting from $3.0 \mathrm{~h}$ for skin type I and increasing up to $7.7 \mathrm{~h}$ for skin type IV. This trend in $\mathrm{t}_{\mathrm{MED}}$, min regarding the skin type is significant $(p<0.001)$. One MED of skin type V and VI could only be exceeded on $\mathrm{N}=4$ and $\mathrm{N}=1$ UVI 1 days in the sample, respectively (values of $t_{M E D, \min }: 8.2,10.2,10.8,10.8$, and $12.7 \mathrm{~h}$, respectively). However, for UVI 2 days, median $t_{\mathrm{MED} \text {, min }}$ is only 1.2 and $1.5 \mathrm{~h}$ for skin types I and II, respectively and $2.7,4.5,6.5$, and $7.35 \mathrm{~h}$ for skin types III, IV, V, and VI. Again, this trend could be shown to be significant $(p<0.001)$. 


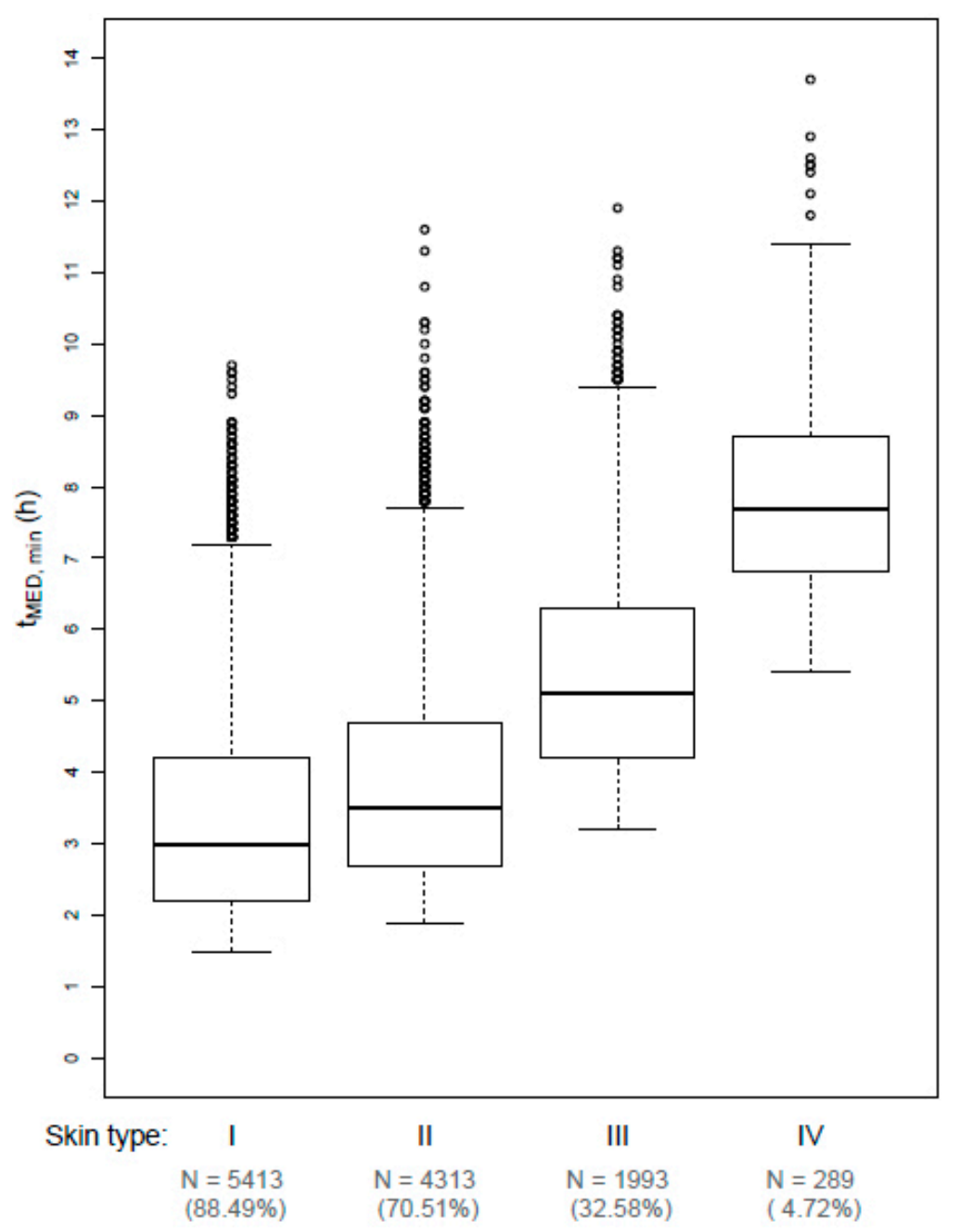

Figure 3. Boxplots of daily minimum exposure durations (in hours) needed to receive one MED $\left(t_{\mathrm{MED}, \mathrm{min}}\right)$ for skin types I-IV for days with rounded UVI values of 1 . Bold line: median, lower/upper edge of box: $25 \% / 75 \%$ quantile (first/third quartile), whiskers: range of data points which are no more than 1.5 times the interquartile range out of the box, dots: outliers. $\mathrm{N}(\%)$ denotes the absolute (relative) number of observations in the subsample, i.e., the absolute (relative) number of UVI 1 days for which one MED could actually be received. The trend in $t_{M E D \text {,min }}$ with respect to skin type can be considered significant $(p<0.001)$. 


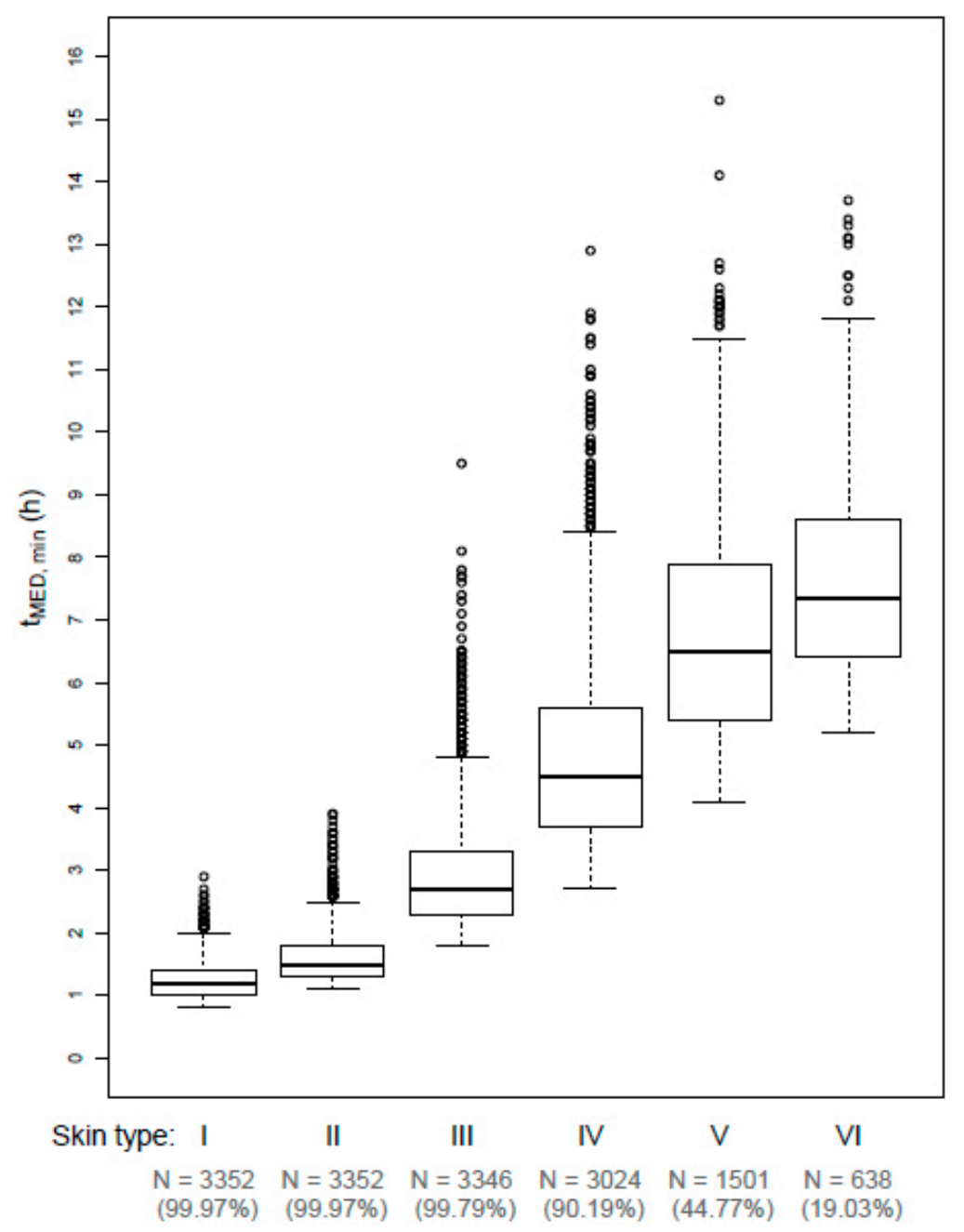

Figure 4. Boxplots of daily minimum exposure durations (in hours) needed to receive one MED $\left(\mathrm{t}_{\mathrm{MED}, \mathrm{min}}\right)$ for skin types I-VI for days with rounded UVI values of 2 . Bold line: median, lower/upper edge of box: $25 \% / 75 \%$ quantile (first/third quartile), whiskers: range of data points which are no more than 1.5 times the interquartile range out of the box, dots: outliers. $\mathrm{N}(\%)$ denotes the absolute (relative) number of observations in the subsample, i.e., the absolute (relative) number of UVI 2 days for which one MED could actually be received. The trend in $t_{M E D \text {,min }}$ with respect to skin type can be considered significant $(p<0.001)$.

\section{Discussion}

Our analysis of $\mathrm{E}_{\mathrm{er}}$ measurement data of days with low UVI values from the German solar UV monitoring network demonstrated that MEDs are exceeded on many UVI 2 days after a few hours of outdoor exposure, especially for the fair skin types I and II. Thus, UVI 2 days in mid-latitude regions like Germany carry an erythemal risk for those staying outdoors for longer periods, especially when belonging to the subgroup of melano-compromised skin types. By contrast, MEDs are exceeded for just a negligibly small number of UVI 0 days under extreme exposure conditions and for a considerable number of UVI 1 days after prolonged exposure around noon for the melano-compromised skin types. UVI 0 days therefore do not seem to pose an erythemal risk, while this risk is very limited on UVI 1 days and restricted to specific skin types. The melano-protected skin types V and VI generally show a negligible risk of erythema arising from the low UVI category, as their MEDs could only even be exceeded after nearly day-long exposure on UVI 2 days and, in extremely rare cases, UVI 1 days. Overall, marked differences between skin types in terms of percentages of days for which one MED is exceeded for a given time interval and minimal exposure durations to receive one MED have been 
illustrated in our analysis, reflecting known differences in susceptibility to UV damages between different skin types.

When the UVI was introduced in 1995, it was already intended to be used as an "integral component of a program to inform the public about UV health risks" [12]. However, a coordinated guidance concerning sun protection measures recommended for specific UVI values was not implemented on the international level at that time. Several local variations of grouping UVI values into categories emerged [27]. In Germany, the Commission on Radiological Protection's (SSK's) official recommendation was that only UVI values of 0 and 1 formed the category 'low' with sun protection not necessary [28]. This matches our results better than the harmonized recommendations provided by WHO, WMO, UNEP, and ICNIRP in 2002 [16]. These latter criteria, including UVI 2 in the 'low' category, were later adopted by SSK to avoid differences in reporting and confusion of the public [29], although the WHO document explicitly states that the UV reporting and sun protection scheme can be varied at the national or local level [16].

In 2012, however, a report from the UVI working group of ICNIRP [17] stated that sun protection might be recommended even at such 'low' UV exposure for people who sunburn easily and plan to stay outdoors for prolonged periods. Notwithstanding, the general threshold for recommending sun protection only at UVI levels of 3 and above was reconfirmed, without specific evidence supporting this decision being mentioned. Still, ICNIRP provides guidelines on limits of exposure to UV radiation [24], which claim an exposure limit of $30 \mathrm{~J} / \mathrm{m}^{2}$ in an $8 \mathrm{~h}$ period. The action spectrum used in these guidelines is different from the erythema reference action spectrum of the International Commission on Illumination $[14,15]$ which is used to calculate $\mathrm{E}_{\mathrm{er}}$. Therefore, this threshold corresponds to 1.0-1.3 SED [25], which would be exceeded in even shorter periods than those needed to receive one MED of the most sensitive skin type I. Although the threshold is aimed primarily at outdoor workers, it is also claimed to be generally valid [24]. ICNIRP itself relaxes this exposure limit by stating that it should be interpreted only as a "desirable goal" for skin exposure (but as a strict limit for ocular exposure) and that it is tailored to the melano-compromised skin types I and II [24]. This limit does not match the UVI health messages and is not mentioned in the official UVI documents.

A report from the UVI 2015 Workshop in Melbourne, Australia [30], also hints towards a basic problem concerning health risks associated with low UVI exposure: The discussion on this topic focused solely on reviewing evidence of harmful biological effects like DNA damage and immunosuppression owing to sub-erythemal UV exposure, thereby assuming that-contrary to the results of our analysis-exposure effects on low UVI days will be limited to the sub-erythemal level. Still, some countries have implemented sun protection messages for the low exposure category which are more cautious than those given in the WHO recommendation. The United States Environmental Protection Agency has recommended covering up and using sunscreen during low UVI conditions if one burns easily since 2004 [31,32]. The Australian Bureau of Meteorology states on its website that sun protection on days with UVI values of 1 or 2 is "generally not needed unless outside for extended periods" [33]. Both phrases essentially link the low UVI exposure category to 'low risk' instead of to 'no risk' as proclaimed by the WHO and its partner organizations.

Our analysis, an extension of a pilot study from 2017 [34] and an addition to recent evidence from New Zealand [35,36], implies that recommending sun protection on UVI 2 days should be discussed during a process of updating current public health messages connected to different UVI levels. Unprotected longer outdoor stays on UVI 2 days, especially around noon, should no longer be labeled as harmless. Keeping the current recommendations could be particularly risky for the population in early spring (March) when a lot of UVI 2 days occur and people uncover greater areas of their skin due to rising temperatures although their skin has not yet adapted to higher UV radiation exposure. Future UV guidance should also avoid labeling any level of the UVI as carrying 'no risk' as current evidence suggests that there is no threshold dose of UV radiation for the induction of skin cancer and thus no safe limit of exposure [37]. In addition, the adaptation of UVI guidance to different skin types should also be considered. Up to today, a 'one size fits all' approach has been 
used, most probably because of the general notion to keep health messages to the public as simple as possible. Nevertheless, the complex situation in this case may still suggest the use of different health messages for different skin types as the potential risk for erythema ranges from considerable for melano-compromised skin types to negligible for melano-protected skin types on UVI 2 days. When doing so, one has to consider that there is a minority of individuals who cannot be classified according to the Fitzpatrick scale and that the accuracy of self-assessed skin types is limited and should therefore be verified by a dermatologist [38]. Despite these minor impediments, local health authorities could choose those messages suitable for the most sensitive major subgroup of a country or region. A similar solution, though resulting from an analysis primarily focusing on very high instead of low UVI values, has been proposed by other authors already [39]. Both the necessity for local adaptation and the possibility of incorporating skin type and exposure duration in the UVI guidance have already been discussed at the WHO UVI workshop in Melbourne in 2015 [30], but have not yet been implemented.

The strength of our analysis lies in the evaluation of a large dataset comprising measurement data of 10 consecutive years from 9 measuring stations of a solar UV monitoring network with a well-established system of quality control and a geographical distribution of the stations giving a representative sample of places in Germany where people expose themselves to the sun. In total, 14,431 daily $\mathrm{E}_{\mathrm{er}}$ time series from days of the 'low' UVI category were available. Such an analysis of measurements capturing the variability of diurnal courses of $E_{e r}$ under real-world conditions is superior to the mere mathematical derivation of UV doses by modeling the diurnal course of $\mathrm{E}_{\mathrm{er}}$ through the use of, e.g., Gaussian-like or even constant functions.

Still, our study suffers from some limitations. For our analysis, we implicitly assumed validity of the Bunsen-Roscoe reciprocity law [40]. That is to say, we implied that the erythemal impact of UV radiation in human skin is directly proportional to the total energy dose but does not depend on the exposure duration needed to apply this dose. Research on this topic is comparatively scarce [41], but in a review from 2003 [42], reciprocity regarding erythema was shown to hold in most studies. Still, this law cannot necessarily be adapted to exposure scenarios incorporating breaks. Repair mechanisms could lead to doses resulting from interrupted exposure being subadditive, whereby sums of doses from our analysis, e.g., for intervals in the morning and the afternoon, could then only be seen as an upper threshold for estimating the actual effect in human skin.

Our dataset consists of ambient erythemal irradiance data which are measured on horizontal detectors. Due to this, the measurements potentially just weakly approximate individual exposure as most human skin surfaces are not oriented horizontally. On the one hand, surfaces facing the sun (almost) vertically can receive significantly higher irradiances (up to $40 \%$ ) during periods without cloud obstruction and with high SZA (i.e., with the sun low in the sky) [43]. The majority of days in our sample (more than $90 \%$ of UVI 0 and 1 days and more than $60 \%$ of UVI 2 days) originate from the autumn and winter period and are therefore likely to represent this scenario. On the other hand, cloudy conditions can reduce UV on tilted surfaces by up to $50 \%$ in comparison to horizontal-incidence UV [43]. Cloudy conditions are likely to have been prevalent on many days in our sample during the late spring and summer period, because only a thick cloud cover sufficiently attenuates UV radiation which would otherwise be much higher during this time of the year. Moreover, the ratio between personal and ambient exposure, frequently called exposure ratio (ER), is highly dependent on individual behavior. This covers aspects like use of shade [44], intermittent indoor activities, and body posture [45]. Values of ER for outdoor workers reported in a review from 2011 ranged from 8-66\% (arms and wrists), $11-85 \%$ (vertex) and $11-70 \%$ (shoulders), respectively [46]. Values for ER are, of course, even lower for indoor workers who spend less time outside in the sun than outdoor workers. A recent study from New Zealand found values of less than $2 \%$ for ER of indoor workers [47]. Still, the official UVI guidelines for the low exposure category should also be valid for a 'worst case' scenario of staying outside for prolonged periods with no sun protection applied. This scenario is what we apply in our analysis. 
Textile protection of the skin is also not considered in our study. Adequate clothing can protect human skin from deleterious UV exposure, the amount of protection depending on the coverage level of the body surface area, and the quality of UV protection offered by the fabric [48,49]. Most of the days in our sample were in autumn and winter when people-due to low ambient temperatures—tend to cover most of their body by clothes offering a high level of UV protection. Still, the body parts that mostly remain uncovered are the hands and the face, which are both common localizations of skin malignancies [50] and are also oriented vertically while standing. This can, as discussed above, lead to even higher irradiances and doses because of the high SZA in this period of the year.

Finally, our analysis focuses on negative health-related aspects of UV exposure on days with low UVI values, namely, the induction of erythema. In the course of potentially adapting UVI guidance to our results, positive health-related aspects of UV exposure like production of vitamin D [2,51-53] should also be considered.

\section{Conclusions}

Current WHO guidance for sun protection on days with 'low' UVI values needs reconsideration. Our analysis revealed that UV exposure for prolonged exposure durations on UVI 2 days and, under certain rare circumstances, even on UVI 1 days, reaches erythemal levels, and thus, sun protection is required to avoid deleterious effects. This particularly relates to sensitive skin types, which might imply the need for skin type specific public health messages relating to the UVI.

Author Contributions: Conceptualization, M.L., W.U., and O.G.; Data curation, M.L.; Formal analysis, M.L.; Investigation, H.S.; Methodology, M.L. and O.G.; Project administration, O.G.; Supervision, A.B.P. and O.G.; Validation, H.S.; Visualization, M.L.; Writing—original draft, M.L.; Writing—review and editing, A.B.P., H.S., W.U., and O.G.

Funding: This research was funded by the Friedrich-Alexander-Universität Erlangen-Nürnberg and received no external funding.

Acknowledgments: We acknowledge support by Friedrich-Alexander-Universität Erlangen-Nürnberg (FAU) within the funding program Open Access Publishing of the university library. We would like to thank all institutions involved in the German solar UV monitoring network for providing their data for this study. These institutions are: Federal Institute for Occupational Safety and Health, German Federal Office for Radiation Protection, University of Kiel, German Weather Service, Labor Inspectorate of Lower Saxony, Bavarian Environmental Agency, German Federal Environmental Agency. Especially, we would like to thank Markus Wallasch (German Federal Environmental Agency) for his support in special aspects of data interpretation. Maria Lehmann performed the present work in partial fulfillment of the requirements for obtaining the degree 'Dr. rer. biol. hum.' at Friedrich-Alexander-Universität Erlangen-Nürnberg.

Conflicts of Interest: The authors declare no conflict of interest.

\section{References}

1. International Agency for Research on Cancer. IARC working group on the evaluation of carcinogenic risk to humans. Radiation. In IARC Monographs on the Evaluation of Carcinogenic Risks to Humans, no. 100d.; IARC: Lyon, France, 2012.

2. Lucas, R.M.; McMichael, A.J.; Armstrong, B.K.; Smith, W.T. Estimating the global disease burden due to ultraviolet radiation exposure. Int. J. Epidemiol. 2008, 37, 654-667. [CrossRef] [PubMed]

3. Erdmann, F.; Lortet-Tieulent, J.; Schuz, J.; Zeeb, H.; Greinert, R.; Breitbart, E.W.; Bray, F. International trends in the incidence of malignant melanoma 1953-2008-are recent generations at higher or lower risk? Int. J. Cancer 2013, 132, 385-400. [CrossRef] [PubMed]

4. Leiter, U.; Eigentler, T.; Garbe, C. Epidemiology of skin cancer. Adv. Exp. Med. Biol. 2014, 810, 120-140. [PubMed]

5. Gefeller, O.; Uter, W.; Pfahlberg, A.B. Protection from ultraviolet radiation during childhood: The parental perspective in Bavaria. Int. J. Environ. Res. Public Health 2016, 13, 1011. [CrossRef]

6. Kasparian, N.A.; McLoone, J.K.; Meiser, B. Skin cancer-related prevention and screening behaviors: A review of the literature. J. Behav. Med. 2009, 32, 406-428. [CrossRef]

7. Narayanan, D.L.; Saladi, R.N.; Fox, J.L. Review: Ultraviolet radiation and skin cancer. Int. J. Dermatol. 2010, 49, 978-986. [CrossRef] 
8. Stanton, W.R.; Janda, M.; Baade, P.D.; Anderson, P. Primary prevention of skin cancer: A review of sun protection in Australia and internationally. Health Promot. Int. 2004, 19, 369-378. [CrossRef]

9. Stratton, S.P. Prevention of non-melanoma skin cancer. Curr. Oncol. Rep. 2001, 3, 295-300. [CrossRef]

10. Beck, N.; Balanay, J.A.G.; Johnson, T. Assessment of occupational exposure to heat stress and solar ultraviolet radiation among groundskeepers in an eastern north carolina university setting. J. Occup. Environ. Hyg. 2018, 15, 105-116. [CrossRef]

11. Morabito, M.; Grifoni, D.; Crisci, A.; Fibbi, L.; Orlandini, S.; Gensini, G.F.; Zipoli, G. Might outdoor heat stress be considered a proxy for the unperceivable effect of the ultraviolet-induced risk of erythema in florence? J. Photochem. Photobiol. B-Biol. 2014, 130, 338-348. [CrossRef]

12. International Commission on Non-Ionizing Radiation Protection. Global Solar UV Index-A Joint Recommendation of the WHO, WMO, UNEP and the ICNIRP; International Commission on Non-Ionizing Radiation Protection: Oberschleissheim, Germany, 1995.

13. Fioletov, V.; Kerr, J.B.; Fergusson, A. The UV index: Definition, distribution and factors affecting it. Can. J. Public Health. 2010, 101, I5-I9. [PubMed]

14. Commission Internationale de l'Eclairage (CIE). Erythema reference action spectrum and standard erythema dose. In ISO 17166:1999(E)/CIE S 007/E-1998; CIE Central Bureau: Vienna, Austria, 1998.

15. Webb, A.R.; Slaper, H.; Koepke, P.; Schmalwieser, A.W. Know your standard: Clarifying the cie erythema action spectrum. Photochem. Photobiol. 2011, 87, 483-486. [CrossRef] [PubMed]

16. World Health Organization. Global Solar UV Index: A Practical Guide; WHO: Geneva, Switzerland, 2002.

17. Allinson, S.; Asmuss, M.; Baldermann, C.; Bentzen, J.; Buller, D.; Gerber, N.; Green, A.C.; Greinert, R.; Kimlin, M.; Kunrath, J.; et al. Validity and use of the UV index: Report from the UVI working group, Schloss Hohenkammer, Germany, 5-7 December 2011. Health Phys. 2012, 103, 301-306. [CrossRef] [PubMed]

18. Sandmann, H. Das solare UV-Messnetz des BfS/UBA. In StrahlenschutzPRAXIS; TÜV Media GmbH: Cologne, Germany, 2015; pp. 38-40.

19. Schmalwieser, A.W.; Grobner, J.; Blumthaler, M.; Klotz, B.; De Backer, H.; Bolsee, D.; Werner, R.; Tomsic, D.; Metelka, L.; Eriksen, P.; et al. UV index monitoring in Europe. Photochem. Photobiol. Sci. 2017, 16, 1349-1370. [CrossRef] [PubMed]

20. Lehmann, M.; Sandmann, H.; Pfahlberg, A.B.; Uter, W.; Gefeller, O. Erythemal UV radiation on days with low UV index values-An analysis of data from the German solar UV monitoring network over a ten-year period. Photochem. Photobiol. 2019. [CrossRef] [PubMed]

21. Fitzpatrick, T.B. The validity and practicality of sun-reactive skin types I through VI. Arch. Dermatol. 1988, 124, 869-871. [CrossRef]

22. Feister, U.; Laschewski, G.; Grewe, R.D. UV index forecasts and measurements of health-effective radiation. J. Photochem. Photobiol. B 2011, 102, 55-68. [CrossRef] [PubMed]

23. R Core Team. R: A Language and Environment for Statistical Computing; R Foundation for Statistical Computing: Vienna, Austria, 2018.

24. International Commission on Non-Ionizing Radiation Protection. Guidelines on limits of exposure to ultraviolet radiation of wavelengths between $180 \mathrm{~nm}$ and $400 \mathrm{~nm}$ (incoherent optical radiation). Health Phys. 2004, 87, 171-186. [CrossRef]

25. International Commission on Non-Ionizing Radiation Protection. Protection of workers against ultraviolet radiation. Health Phys. 2010, 99, 66-87. [CrossRef] [PubMed]

26. Trenberth, K.E. What are the seasons. Bull. Am. Meteorol. Soc. 1983, 64, 1276-1282. [CrossRef]

27. Repacholi, M.H. Global solar UV index. Radiat. Prot. Dosim. 2000, 91, 307-311. [CrossRef]

28. Matthes, R. Global Solar UV-Index, Environmental UV-Radiation, Risk of Skin Cancer and Primary Prevention, Hamburg, Germany, 1996; Federal Ministry of the Environment, Nature Conservation and Nuclear Safety: Hamburg, Germany, 1996.

29. Commission on Radiological Protection. Die neue Klassifikation des Solaren UV-Index (UVI)_Anpassung an Die Internationale Empfehlung der WHO; Commission on Radiological Protection: Bonn, Germany, 2004.

30. Gies, P.; van Deventer, E.; Green, A.C.; Sinclair, C.; Tinker, R. Review of the global solar UV index 2015 workshop report. Health Phys. 2018, 114, 84-90. [CrossRef] [PubMed]

31. United States Environmental Protection Agency. UV Index Scale. Available online: https://www.epa.gov/ sunsafety/uv-index-scale-0 (accessed on 15 March 2019). 
32. United States Environmental Protection Agency. A Guide to the UV Index; United States Environmental Protection Agency: Washington, DC, USA, 2004.

33. Australian Government Bureau of Meteorology. About UV and Sun Protection Times. Available online: http://www.bom.gov.au/uv/ (accessed on 15 March 2019).

34. Lehmann, M.; Pfahlberg, A.B.; Sandmann, H.; Uter, W.; Gefeller, O. Implications of low levels of the UV index for sun protection. Stud. Health Technol. Inform. 2017, 243, 25-29. [PubMed]

35. Lucas, R.M.; Neale, R.E.; Madronich, S.; McKenzie, R.L. Are current guidelines for sun protection optimal for health? Exploring the evidence. Photochem. Photobiol. Sci. 2018, 17, 1956-1963. [CrossRef] [PubMed]

36. McKenzie, R.L.; Lucas, R.M. Reassessing impacts of extended daily exposure to low level solar UV radiation. Sci. Rep. 2018, 8, 13805. [CrossRef] [PubMed]

37. European Commission. Opinion on Biological Effects of Ultraviolet Radiation Relevant to Health with Particular Reference to Sunbeds for Cosmetic Purposes; Scientific Committee on Health, Environmental and Emerging Risks: Luxembourg, 2016.

38. Eilers, S.; Bach, D.Q.; Gaber, R.; Blatt, H.; Guevara, Y.; Nitsche, K.; Kundu, R.V.; Robinson, J.K. Accuracy of self-report in assessing fitzpatrick skin phototypes i through viassessing fitzpatrick skin phototypes i-viassessing fitzpatrick skin phototypes i-vi. JAMA Dermatol. 2013, 149, 1289-1294. [CrossRef] [PubMed]

39. Zaratti, F.; Piacentini, R.D.; Guillen, H.A.; Cabrera, S.H.; Liley, J.B.; McKenzie, R.L. Proposal for a modification of the UVI risk scale. Photochem. Photobiol. Sci. 2014, 13, 980-985. [CrossRef] [PubMed]

40. Bunsen, R.; Roscoe, H. Photochemische untersuchungen. Annalen der Physik 1857, 176, 43-88. [CrossRef]

41. Schindl, A.; Rosado-Schlosser, B.; Trautinger, F. The reciprocity rule in photobiology. A review. Hautarzt 2001, 52, 779. [CrossRef]

42. Martin, J.W.; Chin, J.W.; Nguyen, T. Reciprocity law experiments in polymeric photodegradation: A critical review. Prog. Organ. Coat. 2003, 47, 292-311. [CrossRef]

43. McKenzie, R.L.; Paulin, K.J.; Kotkamp, M. Erythemal UV irradiances at lauder, new zealand: Relationship between horizontal and normal incidence. Photochem. Photobiol. 1997, 66, 683-689. [CrossRef] [PubMed]

44. Sandmann, H.; Stick, C. Spectral and spatial UV sky radiance measurements at a seaside resort under clear sky and slightly overcast conditions. Photochem. Photobiol. 2014, 90, 225-232. [CrossRef] [PubMed]

45. Vernez, D.; Milon, A.; Vuilleumier, L.; Bulliard, J.L.; Koechlin, A.; Boniol, M.; Dore, J.F. A general model to predict individual exposure to solar UV by using ambient irradiance data. J. Expo. Sci. Environ. Epidemiol. 2015, 25, 113-118. [CrossRef] [PubMed]

46. Siani, A.M.; Casale, G.R.; Sisto, R.; Colosimo, A.; Lang, C.A.; Kimlin, M.G. Occupational exposures to solar ultraviolet radiation of vineyard workers in tuscany (italy). Photochem. Photobiol. 2011, 87, 925-934. [CrossRef] [PubMed]

47. Scragg, R.K.R.; Stewart, A.W.; McKenzie, R.L.; Reeder, A.I.; Liley, J.B.; Allen, M.W. Sun exposure and 25-hydroxyvitamin D3 levels in a community sample: Quantifying the association with electronic dosimeters. J. Expo. Sci. Environ. Epidemiol. 2017, 27, 471-477. [CrossRef] [PubMed]

48. Gefeller, O. The garment protection factor: Further advances in labelling sun-protective clothing. Br. J. Dermatol. 2018, 178, 835-836. [CrossRef] [PubMed]

49. Gies, P. Photoprotection by clothing. Photodermatol. Photoimmunol. Photomed. 2007, 23, 264-274. [CrossRef] [PubMed]

50. Stanienda-Sokol, K.; Salwowska, N.; Slawinska, M.; Wicherska-Pawlowska, K.; Lorenc, A.; Wcislo-Dziadecka, D.; Wydmanski, J.; Majewski, W. Primary locations of malignant melanoma lesions depending on patients' gender and age. Asian Pac. J. Cancer Prev. 2017, 18, 3081-3086. [PubMed]

51. Autier, P.; Boniol, M.; Pizot, C.; Mullie, P. Vitamin D status and ill health: A systematic review. Lancet Diabetes Endocrinol. 2014, 2, 76-89. [CrossRef]

52. Holick, M.F. Sunlight and vitamin D for bone health and prevention of autoimmune diseases, cancers, and cardiovascular disease. Am. J. Clin. Nutr. 2004, 80, 1678S-1688S. [CrossRef] [PubMed]

53. Zeeb, H.; Greinert, R. The role of vitamin D in cancer prevention: Does UV protection conflict with the need to raise low levels of vitamin D? Deutsches Arzteblatt Int. 2010, 107, 638-643. 